\title{
Comunicação/educação: campo de ressignificação das tecnologias de comunicação
}

\section{Roseli Fígaro*}

Professora doutora na Escola de Comunicações e Artes da Universidade de São Paulo, com pós-doutorado na Universidade de Provence, França. Pesquisadora do grupo de pesquisa do Arquivo Miroel Silveira, bem como pesquisadora e coordenadora do grupo de pesquisa Comunicação e Trabalho ECA-USP/CNPq. Foi editora executiva da revista Comunicação \& Educação de 1995 a 2003.

Resumo: $O$ artigo trata da importância da compreensão do uso das tecnologias de informação e comunicação no espaço educacional, partindo do princípio de que tais tecnologias são produtos de uma lógica voltada para o mercado cultural, com linguagem e uso bem direcionados, e que ao serem introduzidas na escola passam necessariamente por um processo de ressignificação. Dependendo do projeto educacional da instituição, os educadores terão a tarefa de compreender a complexidade de tais técnicas e linguagens para, utilizando-se delas, reorientá-las, ressignificá-las para a formação de novos cidadãos.

Palavras-chave: novas tecnologias, meios de comunicação, comunicação/educação, escola, professor.
Abstract: This paper discusses the importance of understanding the use of information and communication technologies in the educational space. It is assumed that they are products of the cultural market oriented logic, with well-targeted language and use, and that, once introduced in schools, they go through a process of reinterpretation. Educators must understand such techniques and languages complexities to, by utilization, give them a new direction and signification in the task of forming new citizens.

Keywords: new technologies, media, communication/education, school, teacher.

Comunicação/educação está consolidada como campo do conhecimento com história e com várias linhas de reflexão. Mesmo assim aqui nos cabe o papel de interrogar: para que serve e a quem serve comunicação/educação? A partir de uma visão complexa ${ }^{1}$, responderemos que sem comunicação não há educação. A educação pressupõe um ambiente de interação para se desenvolver. Comunicação/educação serve para conhecer melhor, para ler de maneira mais competente o mundo que nos chega editado. Serve também para dar novos sentidos e novos usos às chamadas tecnologias da informação e da comunicação.

* É autora dos livros: Relações de comunicação no mundo do trabalho; Na cena paulista: o teatro amador. Circuito alternativo e popular de cultura (1927-1945); Comunicação e trabalho: estudo de recepção.

1. MORIN, E. A cabeça bem-feita: repensar a reforma; reformar o pensamento. 6. ed. Rio de Janeiro: Bertrand Brasil, 2002. 
2. Para o conceito de artefato, cf. Folcher, V.; Rabardel, P. Homens, artefatos, atividades: perspectiva instrumental. In Collective and individual uses of a cooperative tool in a work setting problems of design and reuse (Usos coletivos e individuais de instrumentos cooperativos no ambiente de trabalho: problemas de design e reúso). In ternational Conference on the design of cooperative systems, 3. Cannes, 1998. Proceedings: COOP'98. Cannes: INRIA, 1998. p. 25-28.
Os meios de comunicação - jornal, telefone, cinema, rádio, televisão, celular, internet (e-mail, blog, twitter, orkut etc.) - são adventos tecnológicos que reorganizam as relações entre os homens. Redimensionam a noção tempo/ espaço; recolocam a questão do relacionamento entre as culturas apaziguando e, na maioria das vezes, recrudescendo as divergências e conflitos culturais. Aproximam e distanciam pessoas, dependendo do uso para o qual são absorvidos. Foram adquirindo uma linguagem própria, específica, formatada a partir da relação homem/artefato ${ }^{2} /$ homem, objetivando a comunicação midiática.

\section{LÓGICA MERCANTIL ORIENTA USOS E LINGUAGENS DOS MEIOS DE COMUNICAÇÃO}

Escrever para o jornal é diferente de escrever uma carta, por exemplo. E foi ficando cada vez mais distante da carta, do livro, do ofício à medida que foi se adequando a um modo e a um sistema de produção. Isto é, o jornal incorporou-se à vida urbana, à lógica da produção em larga escala, na qual a informação também é mercadoria. $\mathrm{O}$ formato da escritura da informação adquire então característica peculiar, principalmente nos Estados Unidos, criando gêneros jornalísticos como a notícia, a reportagem, a entrevista etc. Formatos que podem tratar de maneiras diferentes o mesmo dado da realidade. Há, portanto, uma lógica de produção que toma o fato como matéria-prima e o transforma em um produto notícia, ou reportagem, ou entrevista etc. Essa maneira de produzir o jornal também exige um modo diferenciado de leitura. Não se pode ler o jornal como se lê uma carta, um livro, um ofício.

Todos os meios de comunicação introduzem um jeito inovador de relacionamento com os outros, com a coletividade. O rádio e a televisão foram revolucionários quanto a esta questão. Falar a um público que ouve rádio é diferente de falar ao telefone. Escrever para o rádio é diferente de escrever para o jornal. Assim como ouvir rádio exige uma interação completamente diferente de ouvir uma conversa atrás da porta, ou de ouvir alguém ao telefone. Acionam-se processos cognitivos diferentes. Exigem-se cumplicidade, conhecimento das regras e dos formatos propostos. Se alguém lhe propõe a audição de um informativo pelo rádio, com certeza você se preparará para ouvir alguma coisa de determinado gênero; se em vez do formato esperado lhe for apresentado o ficcional ou o humorístico, mesmo se tratando de rádio, ele não será encarado como notícia. Assim também é na televisão, no cinema. Assistir a filmes no cinema é diferente de assisti-los na televisão. O noticiário da televisão obedece a um roteiro de produção totalmente diferente daquele estabelecido pela pauta do jornal, ou pelo radiojornalismo.

Além das diferenças introduzidas pelo artefato tecnológico, há outros dispositivos que atuam na formulação da proposta comunicacional. Por exemplo, o gênero, o público, a linguagem verbal escrita ou falada, o som sem a imagem, o som e a imagem; a forma de distribuição ou acesso (impresso, transmitido por ondas sonoras, sinal digital ou analógico). Outros fatores intervenientes, e 
muito relevantes, são aqueles que dizem respeito à organização socioeconômica da sociedade. Incidem sobre os bens a forma econômica de organização de sua produção. O denominado mercado sintetiza, como metáfora, as lógicas e as relações de produção e distribuição dos bens culturais.

Em nossa sociedade o marketing e a publicidade orientam a estética dos meios de comunicação tradicionais. Para Vanni Codeluppi: “[...] o marketing é hoje uma ideologia totalizante que está invadindo completamente o espaço social, ocupando em sua passagem toda uma série de valores próprios da modernidade que estão sendo progressivamente desagregados"3. A partir dessa afirmação, pode-se questionar como as novas mídias estão sendo apropriadas e como estão nascendo os novos gêneros de discursos que elas viabilizam? As denominadas redes sociais serão loteadas pelo mercado? São questões que merecem reflexão.

A forma de organização socioeconômica atua na produção e recepção do produto cultural. Estudos sobre a grade de programação da televisão brasileira indicam essa relação. João Luís Van Tilburg ${ }^{4}$ analisou, em A televisão e o mundo do trabalho, 1990, como a grade de programação da Rede Globo de Televisão atendia e atende à lógica dos horários do público que chega a sua casa depois do trabalho e quer descansar e ter alguma notícia sobre o país. Com esse objetivo foi implantada a grade que, no horário nobre, contemplava (e contempla) novela-novela-telejornal-novela. Mais recentemente, podemos citar diversos autores ${ }^{5}$ que têm estudado como a telenovela, originária do melodrama, é construída em diálogo com a pauta jornalística ou com os temas polêmicos e relevantes do momento; aspectos que interferem, portanto, na estrutura do gênero. A caracterização da telenovela feita no Brasil, como um gênero particular de melodrama para televisão, atende à necessidade de um público que gosta de ter as pautas sociais discutidas por meio das personagens de ficção.

A publicidade também deve ser estudada a partir de sua contribuição para a formação de uma estética e uma linguagem para a televisão. Já nos idos de 1960, as peças publicitárias inovavam mais do que outros formatos televisivos: ritmo, texto, imagem recebiam tratamento diferenciado com o qual a pequena programação da época nem sequer poderia sonhar. Um bom exemplo são as peças publicitárias da Unilever ${ }^{6}$ e seu detergente em pó OMO. Ao longo de 42 anos de história, as peças publicitárias desse sabão são um importante indicador das mudanças pelas quais passaram os recursos tecnológicos, a linguagem publicitária e, sobretudo, a família e a mulher brasileiras. As mudanças sociológicas no perfil da família e da mulher foram lidas pelos produtores das campanhas publicitárias como fatores que não poderiam ficar de fora do apelo comercial do produto; dessa maneira, foram incorporados e tratados, como exemplifica a inserção da mulher no mercado de trabalho, mantendo a responsabilidade das tarefas de mãe, esposa e dona de casa.

A lógica mercantil toma lugar também na internet, que aos poucos vai sendo ocupada pelos grandes provedores e produtores de linguagens com interfaces que permitem acesso a partir da disponibilidade do número do cartão de crédito.
3. CODELUPPI, Vanni. Pensador italiano critica "sociedade publicitária". O Estado de S. Paulo. 7 maio 2002. Caderno 2. Disponível em: <http:// www.estadao.com.br/arquivo/arteelazer/2002/ not20020507p2359.htm>. Acesso em: 5 jul. 2010.

4. VAN TILBURG, João Luís. A televisão e o mundo do trabalho: o poder de barganha do cidadão-telespectador. São Paulo: Paulinas, 1990.

5. MOTTER, M. Telenovela: arte do cotidiano. Comunicação \& Educação, Brasil, v. 5, n. 13, 2007. Disponível em: <http://www.revistas. univerciencia.org/index. php/comeduc/article/ view/4079>. Acesso em: 5 jul. 2010; Telenovela e educação: um processo interativo. Comunicação \& Educação, Brasil, v. 6, n. 17, 2007. Disponível em: <http://www.revistas. univerciencia.org/index. php/comeduc/article/ view/4103>. Acesso em: 5 jul. 2010.

LOPES, Maria Immacolata Vassalo de, et al. Vivendo com a telenovela: mediação, recepção teleficcionalidade. São Paulo: Summus, 2002.

6. Vídeo da Unilever com as peças publicitárias dos últimos 42 anos do produto OMO no Brasil (1960-2002). 
7. Cf. em LACALLE; CHARO. As novas narrativas da ficção televisiva e a Internet. Matrizes: revista do Programa de Pós-graduação em Ciências da Comunicação da Universidade de São Paulo, São Paulo: ECA-USP/ Paulus, ano 3, n. 2, p. 79-102, jan./jul. 2010.
A fusão das diferentes tecnologias, internet, telefone, televisão, computador, cinema, rádio, $\mathrm{CD}$, não tem deixado por menos. A lógica dessas fusões opera-se na formatação de novas linguagens que dão tratamento especial às temáticas $\mathrm{e}$ demandas da sociedade. Tais temáticas e demandas são, no entanto, organizadas pelo embate dos usos orientados pelos cidadãos e pelos interesses comerciais dos grandes conglomerados de mídia.

Como gigantes do porte da Microsoft e do Google atuam nessa seara de disputa do novo mercado virtual? Como as decisões dessas empresas interferem no uso que fazemos das novas mídias?

Como os meios de comunicação atuam nas formas de aprendermos e de nos relacionarmos, há que se ficar atento para os usos que fazemos das novas mídias, sobretudo, as mídias móveis: câmaras, celulares, Ipods etc. O que estamos construindo em termos de fusão de linguagens com os denominados processos transmediáticos?

O computador e as novas tecnologias que permitem o acesso à virtualidade digital inserem-se na realidade a partir da mesma lógica mercantil dos outros artefatos. Os programas que possibilitam uma interface mais amigável com a máquina, até o tipo de tecnologia disponível para o usuário comum, obedecem à lógica do grande capital. A disputa entre a Microsoft e outras empresas é desigual. Veja-se a experiência com o programa Linux, gratuito, que trava uma disputa desproporcional para colocar-se no mercado ocupado quase que totalmente pelo windows.

\section{OS MEIOS E AS TECNOLOGIAS DA COMUNICAÇÃO NO ESPAÇO ESCOLAR}

O primeiro desafio do campo comunicação/educação é o de como abordar a lógica que envolve as tecnologias da comunicação no espaço da escola na sociedade contemporânea. $\mathrm{O}$ que a escola tem a ver com isso, e ela, como instituição, também passa por essa lógica?

A escola precisa estar consciente dos fatores que a envolvem, ou seja, formar para o mercado competitivo, orientado pela lógica do mais forte, ou formar cidadãos para a sociedade democrática e de oportunidades para todos? Buscar o equilíbrio entre esses dois aspectos é tarefa complicada, mas urgente. E é no trabalho com comunicação/educação que se poderá enfrentar de maneira mais explícita tal desafio.

Aí estão os problemas centrais que permeiam o campo comunicação/ educação. A primeira questão a ser decidida, seja usando o computador, seja a lousa e o giz, é em que universo de valores a escola vai trabalhar. E isto não pode ser mascarado com a falta ou a sobra de artefatos tecnológicos.

Para aqueles que se identificam com a visão de que a escola deve se preocupar com um futuro mais promissor em termos de oportunidades, liberdade e democracia para a maioria da população, o problema é bem grande. As 
dificuldades aparecem com radicalidade e nem sempre de forma clara. Enfrenta-se a questão da disponibilidade das novas tecnologias para o maior número de pessoas (escolas) possível. Enfrenta-se o problema de que as tecnologias são introduzidas a partir de uma lógica que já orienta sua utilização num determinado sentido, o mercantil. E, portanto, precisam ser ressemantizadas pelo espaço da educação, da formação humanista e cidadã.

Guillermo Orozco-Gómez trata do assunto ao afirmar que: "A tecnologia não é um resultado inevitável, nem natural, do avanço científico. Toda tecnologia podia e pode ser diferente, podia e pode ser outra, diversa". Orozco cita exemplos de como a TV em cores demorou a chegar ao Canadá, devido ao interesse dos EUA em vender sua programação para TV em branco e preto que não seria mais consumida em solo natal. Outro exemplo a que ele se remete é o uso de censores eletrônicos: enquanto na Alemanha eram usados para controlar o consumo de água, colaborando assim com a necessidade de preservar e economizar esse bem, nos EUA eram utilizados nos shopping centers para abrir e fechar as portas, facilitando o trânsito do consumidor.

Sendo assim, cabe ao campo comunicação/educação reconhecer a importância do advento das novas tecnologias de comunicação, pois elas não podem ficar do lado de fora da escola. Mas cabe prioritariamente a este campo desnaturalizar a lógica mercantil dessas tecnologias, para que elas possam ser ressemantizadas pela lógica da formação humanística, da ação para a educação e a cidadania.

Isso quer dizer que todos os conteúdos e formatos dos meios de comunicação podem cruzar os muros da escola e entrar na sala de aula. Mas também quer dizer que esses conteúdos e formatos precisam ser trabalhados de maneira diferenciada. O professor deve preparar-se para não só fazer a leitura crítica do conteúdo das mensagens dos meios de comunicação, mas, além dela, precisa aliar a essa preocupação aquela que trata de demonstrar como esses formatos e conteúdos são construídos, a que se propõem, que tipo de mercado atendem e como seriam transformados para os fins do cultivo do conhecimento, da cultura, da cidadania, da solidariedade, da arte, da beleza e da alegria.

A escola e o educador que optam pela formação humanista, pensando o cidadão de forma integral, compreenderão o campo comunicação/educação como possibilidade de introduzir no cenário escolar os temas antes abordados e responder a eles de maneira adequada no que diz respeito às tarefas a serem desenvolvidas pelo corpo docente, bem como à postura a ser adotada pelo professor/mediador quanto aos conteúdos curriculares, às atividades didáticas e às formas de avaliação.

Portanto, não há como negar a relevância das tecnologias de comunicação, mas há de se compreender que elas, como artefatos de cultura, clamam pelo protagonismo da ação humana que, na escola, deveria ser direcionada para objetivos que extrapolam, e muito, os interesses mercantis.
8. OROZCO-GÓMEZ, G. Comunicação, educação e novas tecnologias: tríade do século XXI. Comunicação \& Educação, Brasil, v. 8, n. 23, p. 21,2008 . Disponivel em: <http://www. revistas.univerciencia.org/ index.php/comeduc/article/view/4520>. Acesso em: 5 jul. 2010. 
comunicação \& educação • Ano XV • número 3 • set/dez 2010

\section{ARTIGOS NACIONAIS}

Neste número, Comunicação Ė Educação, na seção Artigos Nacionais, traz contribuições ao campo da educomunicação vindas de diferentes abordagens teóricas e temáticas.

O artigo Estudos de recepção para entender os usos da mídia na escola, de Roseli Fígaro, destaca que, se os dispositivos para a comunicação em massa segmentaram a produção e a recepção, simulando um receptor passivo, na atualidade, a web 2 e as redes sociais estão potencializando o processo comunicacional, prometendo dar visibilidade ao papel do sujeito como receptor/produtor de discursos. A autora defende os estudos de recepção como abordagem teórico-metodológica que permite ao pesquisador entender o papel dos meios de comunicação e como eles repercutem no cotidiano dos grupos sociais, nas diferentes comunidades e culturas. Em Cinema de poesia: os germens poéticos que fecundam Lavoura arcaica, Acir Dias da Silva e Deise Ellen Piatti questionam se o filme de Luiz Fernando de Carvalho se configura como cinema de poesia. Tal expressão, criada pelo cineasta Pier Paolo Pasolini, é utilizada por estudiosos do cinema para identificar textos cinematográficos específicos, cuja estética imagem/espaço-temporal seja capaz das sínteses metafóricas da poesia. $\mathrm{O}$ artigo Corpo e tecnologia na sala de aula: estudos contemporâneos, de Wilton Garcia, trata de um tema delicado para a escola: o corpo e as tecnologias móveis - celular, MP4, ipod. O corpo do jovem e o uso e portabilidade das novas tecnologias desafiam o contexto comunicacional no espaço da escola. Em Fotografia e fotoescultura: significação, arte e educação, Ricardo Zani discute a fotografia como material de pesquisa e de arte-educação a partir do conceito de fotoescultura pertinente à arte contemporânea. A contribuição do autor vem no sentido de apresentar uma abordagem de leitura e interpretação do signo não verbal em propostas pedagógicas. Ismar de Oliveira Soares, no artigo Educomunicação e terceiro entorno: diálogos com Galimberti, Echeverría e Martín-Barbero, analisa a presença das tecnologias da informação e da comunicação na sociedade contemporânea, sobretudo no espaço da escola. Ele o faz a partir de um diálogo com os autores citados, problematizando os conceitos de teoria da ação, terceiro entorno e ecossistema comunicativo. A questão que orienta a reflexão proposta pelo autor é o programa da Licenciatura em Educomunicação, que se inicia na ECA-USP em 2011.

\section{ARTIGO INTERNACIONAL}

A colaboração internacional de María del Mar Ramírez Alvarado, Virginia Guarinos Galán, Inmaculada Gordillo Álvarez e Jacqueline Sánchez Carrero, com o artigo Fotografia criativa para as crianças: a alfabetização audiovisual através da fotografia, oferece os resultados das oficinas de fotografia para crianças entre $4 \mathrm{e}$ 12 anos, realizadas em Sevilha (Espanha), em 2009. A experiência demonstrou que as crianças, desde a tenra idade, têm condições de interiorizar noções sobre 
planos, ângulos, perspectiva, sequências e composição, permitindo-lhes maior aproximação com a linguagem fotográfica e com outras manifestações culturais.

\section{GESTÃO DA COMUNICAÇÃO}

Andréa Blum relata, em Observatório da imprensa na internet: uma leitura crítica da mídia brasileira, o diálogo que se construiu com os leitores, desde 1996, objetivando aprimorar o senso analítico sobre o que é veiculado pela imprensa. $\mathrm{O}$ site e a relação on-line com o público trazem ganhos para estreitar o contato com os mais jovens.

\section{ENTREVISTA}

André Barbosa Filho, assessor especial do Gabinete Civil da Presidência da República, dedicado a assuntos relacionados às políticas públicas de comunicação, é o entrevistado deste número. A jornalista Juliana Winkel destaca, na entrevista, questões relativas à banda larga e à televisão digital, tecnologias que interessam diretamente à liberdade de expressão da população e não podem ficar sob a tutela dos interesses particulares de alguns empresários, sobretudo estrangeiros.

\section{CRÍTICA}

A publicidade é o tema do artigo Consumo, identidade e publicidade: uma relação a ser (re)pensada, de Diana Gualberto de Macedo. A autora propõe a reflexão de que a publicidade é uma mola propulsora do processo de produção e distribuição. Afirma ainda que o valor simbólico que a publicidade acrescenta aos produtos possibilita a circulação de comportamentos identitários, associados a estilos de vida.

\section{DEPOIMENTO}

Pedro Bandeira, Jovem escritor de gerações, fala de sua experiência profissional como autor de literatura infantojuvenil, do seu processo criativo e da evolução de sua carreira. Ele é um dos autores mais publicados no país, daí sua autoridade para falar do perfil dos leitores e das carências do cenário educacional brasileiro.

\section{EXPERIÊNCIA}

A interatividade na educação a distância: o papel central da interatividade nos processos de ensino-aprendizagem na EAD, artigo de Alberto Efendy Maldonado 
e Julie Reichert, trata da interatividade como principal aspecto da aprendizagem dos estudantes de ensino a distância. Relata in loco uma experiência com estudantes da turma de laboratório de Gestão I, da Universidade do Vale do Rio dos Sinos.

\section{POESIA}

Comunicação poética: São Paulo sob quatro olhares é o destaque deste número para a seção Poesia. Os autores Adilson Citelli e Cristine Vargas trazem Mário de Andrade, Paulo Vanzolini, Caetano Veloso e Tom Zé. É uma homenagem à cidade que de vila e pequeno entreposto de mulas, no século XIX, passa em menos de três décadas, no início do século XX, à maior cidade do país. Suas contradições são infindas, mas sua beleza é peculiar.

\section{SERVIÇOS}

O Museu Histórico Nacional é a instituição que Ângela Cardoso Guedes apresenta aos leitores. Localizado no centro histórico do Rio de Janeiro, o Museu preserva o maior acervo cultural do país, com cerca de 277.490 itens. O espaço mantém intensa atividade de pesquisa e editoração, além de oferecer ao público exposições, cursos, seminários, visitas monitoradas e treinamento a professores.

\section{VIDEOGRAFIA}

Maria Ignês Carlos Magno nos presenteia com a proposta de leitura e discussão a partir de duas produções audiovisuais. Sob o título Uma novela de Rosa: um auto de Suassuna e um encontro entre o erudito, o popular e o massivo, ela discute a adaptação do cinema para a televisão, bem como o embaralhamento entre a tradicional abordagem esquemática da cultura.

\section{BOLETIM BIBLIOGRÁFICO}

A tradicional seção Boletins Bibliográficos traz sugestões de leitura na área de Comunicação e Educação e de Estudos da ficção seriada televisiva, bem como indicações de pesquisa em Endereços úteis na internet.

\section{ATIVIDADES EM SALA DE AULA}

Tomando como mote os artigos deste número de Comunicação E̊ Educação, Ruth Ribas Itacarambi faz propostas de projetos pedagógicos a serem desenvolvidos com os alunos em sala de aula. 


\section{REFERÊNCIAS BIBLIOGRÁFICAS}

FOLCHER, V.; RABARDEL, P. Homens, artefatos, atividades: perspectiva instrumental. In: Collective and individual uses of a cooperative tool in a work setting: problems of design and reuse (Usos coletivos e individuais de instrumentos cooperativos no ambiente de trabalho: problemas de design e reúso). International Conference on the design of cooperative systems, 3. Cannes, 1998. Proceedings: COOP'98. Cannes: INRIA, 1998.

LACALLE, Charo. As novas narrativas da ficção televisiva e a Internet. Matrizes: revista do Programa de Pós-graduação em Ciências da Comunicação da Universidade de São Paulo, São Paulo: ECA-USP/Paulus, ano 3, n. 2, p. 79-102, jan./jul. 2010.

LOPES, Maria Immacolata Vassalo de, et al. Vivendo com a telenovela: mediação, recepção, teleficcionalidade. São Paulo: Summus, 2002.

MORIN, E. A cabeça bem-feita: repensar a reforma; reformar o pensamento. 6 . ed. Rio de Janeiro: Bertrand Brasil, 2002.

VAN TILBURG, João Luís. A televisão e o mundo do trabalho: o poder de barganha do cidadão-telespectador. São Paulo: Paulinas, 1990.

\section{Endereços eletrônicos}

CODELUPPI, Vanni. Pensador italiano critica "sociedade publicitária". O Estado de S. Paulo, 7 maio 2002. Caderno 2. Disponível em: <http:/ /www.estadao.com. br/arquivo/arteelazer/2002/not20020507p2359.htm>. Acesso em: 5 jul. 2010.

MOTTER, M. Telenovela e educação: um processo interativo. Comunicação \& Educação, Brasil, v. 6, n. 17, 2007. Disponível em: <http://www.revistas. univerciencia.org/index.php/comeduc/article/view/4103>. Acesso em: 5 jul. 2010.

Telenovela: arte do cotidiano. Comunicação \& Educação, Brasil, v. 5, n. 13, 2007. Disponível em: <http://www.revistas.univerciencia.org/index.php/ comeduc/article/view/4079>. Acesso em: 5 jul. 2010.

OROZCO-GÓMEZ, G. Comunicação, educação e novas tecnologias: tríade do século XXI. Comunicação \& Educação, Brasil, v. 8, n. 23, p. 21, 2008. Disponível em: $<$ http://www.revistas.univerciencia.org/index.php/comeduc/article/view/4520 . Acesso em: 5 jul. 2010. 

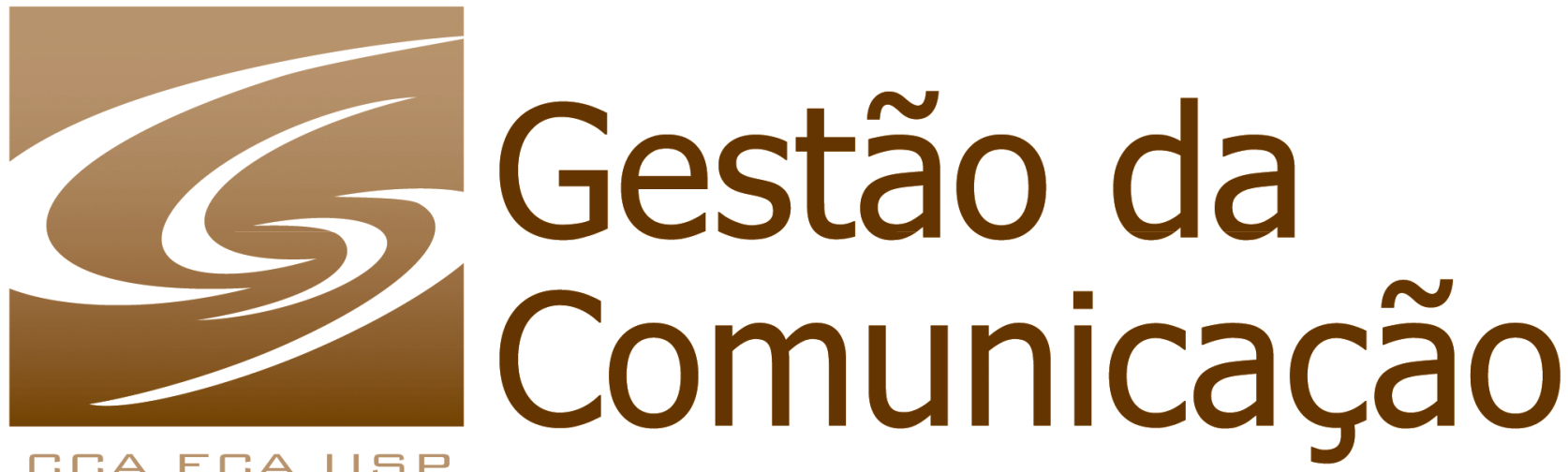

டロA EロA பூ口

\section{O mais experiente e atualizado Curso de Especialização em Comunicação da USP}

O gestor da comunicação planeja e executa projetos de comunicação em empresas privadas, instituições públicas ou movimentos comunitários nas áreas educacional, empresarial ou artístico-cultural.

três semestres

formação superior (qualquer área) prova escrita, entrevista e plano de estudo

turma com aulas de segunda a quarta-feira turma com aulas às sextas-feiras e aos sábados.
Capacitação do aluno para eleborar, implantar, avaliar e reestruturar projetos de comunicação/ cultura.

Integração teórico-prática da área de comunicação com o mercado de trabalho. Formação humanística e profissional sólidas, baseada na inter-relação comunicação/cultura/ artes.

Qualificação do profissional, preparando-o para compreender o mercado emergente, em constante transformação, e agir sobre ele. eca

usp

Departamento de

Comunicações e Artes

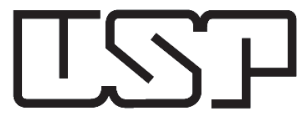

(+5511) 3091-4341

+551 1 3091-4867

www.eca.usp.br/ gestcom@usp.br
Av. Prof. Lúcio Martins

Rodrigues, 443, sl 209

Cidade Universitária São Paulo SP 